\title{
Incidental appendicitis in a blunt trauma patient: a case report
}

Received September 9, 2021

Revised September 16, 2021

Accepted October 8, 2021

Correspondence to

Pil Young Jung

Department of Surgery, Yonsei

University Wonju College of Medicine,

20 Ilsan-ro, Wonju 26426, Korea

Tel: +82-33-741-0882

Fax: +82-33-741-0574

E-mail: surgery4trauma@yonsei.ac.kr

\section{KwangJin Lee, Pil Young Jung}

Department of Surgery, Yonsei University Wonju College of Medicine, Wonju, Korea

Acute appendicitis is a relatively common disease, but it is rarely caused by trauma. There are some reports on appendicitis caused by blunt abdominal trauma, but the pathophysiology is still uncertain. In this report, we presented a case of a patient who developed acute appendicitis following blunt trauma to the abdomen sustained during a motor vehicle accident.

Key Words: Appendicitis, Appendectomy, Abdominal injury

\section{Introduction}

Appendicitis caused by trauma is rare and difficult to predict in the case of patients visiting for severe trauma. In this report, we present a case of a patient who developed acute appendicitis following blunt trauma to the abdomen sustained during a motor vehicle accident.

\section{Case presentation}

A 68-year-old woman was transferred to our regional trauma center after a motor vehicle accident. The patient was sitting with a fastened seat belt in the passenger seat of a vehicle that was struck on the front end by another vehicle. The patient was conscious, but her vital signs were as follows: blood pressure, 53/26 $\mathrm{mmHg}$; heart rate, 106 bpm; and temperature, $36.5^{\circ} \mathrm{C}$. Laboratory investigations revealed hemoglobin $(\mathrm{Hb})$ of $9.8 \mathrm{~g} / \mathrm{dl}$ and white blood cell count of $13,370 / \mathrm{mm}^{3}$. Physical examination revealed a distended and diffusely tender abdomen. Extended fo- cused assessment with sonography for trauma (eFAST) showed the presence of peritoneal fluid in the Morison's pouch. After fluid resuscitation, her blood pressure had risen to $131 / 53 \mathrm{mmHg}$, and abdominal computed tomography (CT) scan was performed. The CT scan showed hemoperitoneum around the liver, small bowel mesentery, pelvic cavity, and a dilated appendix with wall enhancement and periappendiceal fat infiltration (Fig. 1). Furthermore, multiple mesenteric tears, small bowel perforation, and a Grade II spleen injury were detected at laparotomy (Fig. 2). On further exploration, acute appendicitis was encountered (Fig. 3). Segmental small bowel resection, splenectomy, and appendectomy were performed (Fig. 4). Postoperatively, the diagnosis of appendicitis was confirmed pathologically. After 13 days, a follow-up CT scan showed a small fluid collection in the intraperitoneal and retroperitoneal spaces and right lower abdominal wall, but no active lesion was evident. The postoperative course was uneventful, and she was discharged on postoperative day 16.

(c)This is an Open Access article distributed under the terms of the Creative Commons Attribution Non-Commercial License (http://creativecommons.org/licenses/by-nc/4.0) which permits unrestricted noncommercial use, distribution, and reproduction in any medium, provided the original work is properly cited.

Copyright (C) 2021 Korean Association for Research, Procedures and Education on Trauma. All rights reserved. 


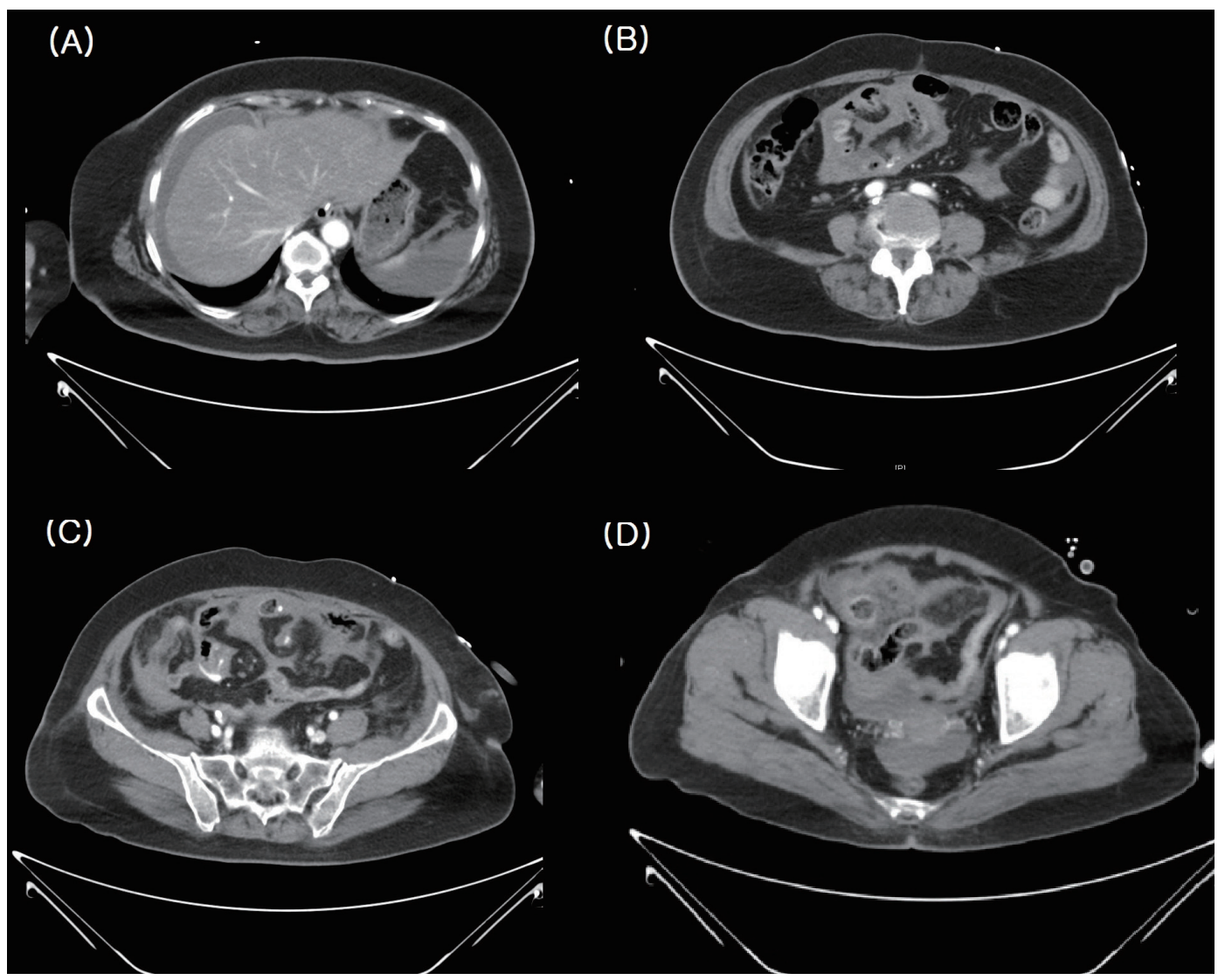

Fig. 1. Abdominal computed tomography (CT) performed in the emergency department. (A) Hemoperitoneum around the liver, (B) small bowel mesentery, (C) dilated appendix with wall enhancement and periappendiceal fat infiltration, and (D) pelvic cavity.

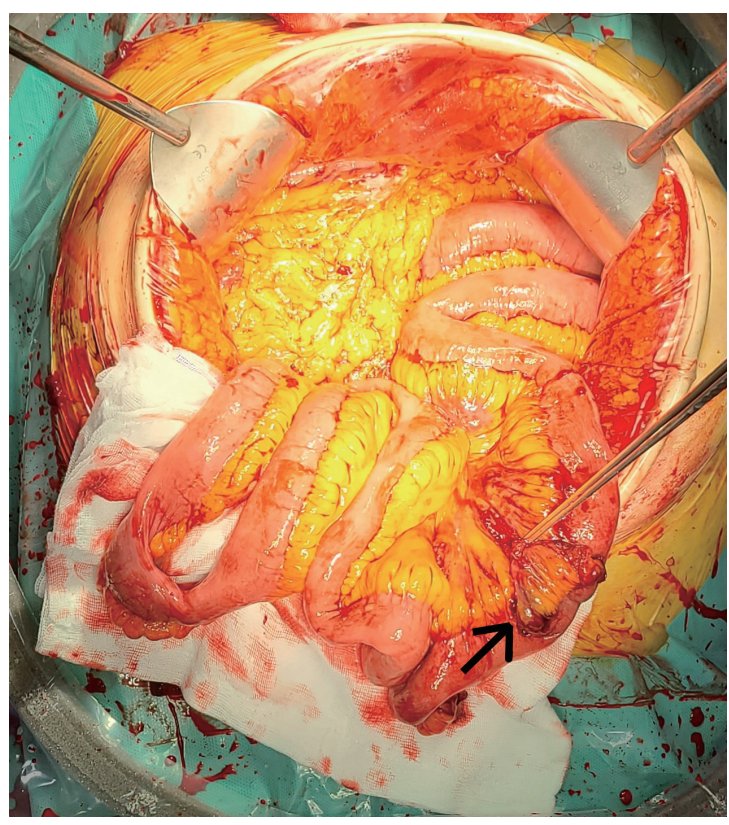

Fig. 2. Operative findings: mesenteric tear and small bowel perforation (arrow).

\section{Discussion}

Appendicitis typically results from luminal obstruction by miscellaneous factors, including inspissated stool, foreign bodies, and intestinal parasites (1). Whether appendicitis can be induced by blunt abdominal trauma (BAT) is uncertain, but several theories exist. First, the increased intra-abdominal pressure by BAT increases the lumen pressure of the appendix (2). Second, blunt trauma might have a direct effect on the appendix with subsequent appendiceal edema and hyperplasia of the intrinsic lymphoid tissues, all of which could result in appendiceal lumen obstruction (3). Third, hematoma caused by intraperitoneal hemorrhage can produce a significant decrease in visceral arterial blood flow, followed by edema of the bowel wall (4). Furthermore, many other hypotheses have been raised but because of the lack of cases and absence of verification methods, it is difficult to identify the pathogenesis of trauma-induced appendicitis. Some papers suggest the 


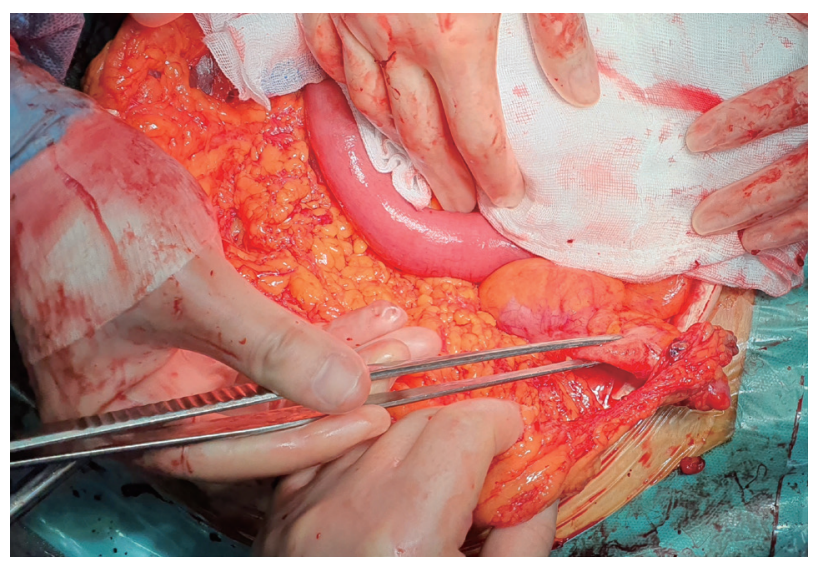

Fig. 3. Operative findings: incidental appendicitis.

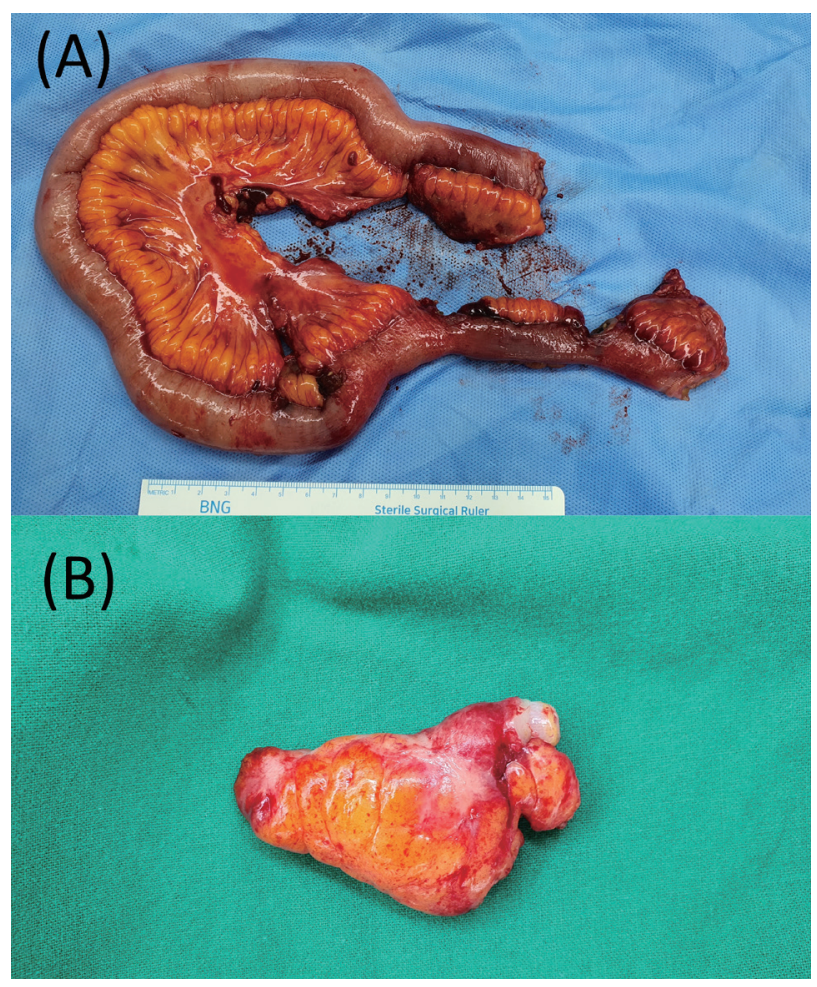

Fig. 4. (A) Specimens with perforated small bowel cut. (B) Inflammatory appendix. possibility of preexisting appendicitis just before BAT (5). In this case, appendicitis occurred before the trauma and was discovered by accident in tests conducted for trauma without the patient knowing it. However, before the trauma, the patient was not diagnosed with any unusual abdominal symptoms, and it is difficult to validate the truth because the operation findings are close to chronic inflammation. If an appendectomy is missed during open surgery, an additional appendectomy can be difficult because of problems such as intestinal edema and adhesion due to the previous surgery.

\section{Conflict of interest}

No potential conflict of interest relevant to this article was reported.

\section{References}

1. Ciftci AO, Tanyel FC, Buyukpamukcu N, Hicsonmez A. Appendicitis after blunt abdominal trauma: cause or coincidence? Eur J Pediatr Surg. 1996;6(6):350-3.

2. Fowler RH. The rare incidence of acute appendicitis resulting from external trauma. Ann Surg. 1938; 107(4):529-39.

3. Etensel B, Yazici M, Gursoy H, Ozkisacik S, Erkus M. The effect of blunt abdominal trauma on appendix vermiformis. Emerg Med J. 2005;22(12):874-7.

4. Schein M, Klipfel A. Local peritoneal responses in peritonities-clinical scenarios I: peritoneal compartment responses and its clinical consequences. Sepsis. 1999;3(4):327-33.

5. Toumi Z, Chan A, Hadfield MB, Hulton NR. Systematic review of blunt abdominal trauma as a cause of acute appendicitis. Ann R Coll Surg Engl. 2010;92(6): 477-82. 